\section{Propostas governamentais brasileiras de ações de prevenção e controle do sobrepeso e obesidade sob perspectiva municipal}

\author{
Brazilian government proposals for actions to \\ prevent and control overweight and obesity \\ from a local perspective
}

\section{Propuestas de acciones gubernamentales brasileñas para la prevención y control del sobrepeso y obesidad desde una perspectiva municipal}

\author{
Doralice Batista das Neves Ramos 1 \\ Luciene Burlandy 1 \\ Patrícia Camacho Dias 1 \\ Patrícia Henriques 1 \\ Luciana Maria Cerqueira Castro 2 \\ Márcia Regina Mazalotti Teixeira ${ }^{3}$ \\ Cláudia Roberta Bocca 4 \\ Thays da Silva Araujo 1 \\ Fernando de Andrade Caldas 1 \\ Thamillys Rodrigues Souza 1 \\ Simone Raimondi de Souza 5 \\ Myrian Coelho Cunha Cruz 6
}

\section{Resumo}

O presente artigo analisa as ações de prevenção e controle do sobrepeso e da obesidade que vêm sendo desenvolvidas nos 92 municípios do Estado do Rio de Janeiro, Brasil, com base em princípios que fundamentam a tipologia clássica de politicas públicas desenvolvidas por Lowi e a Linha de Cuidado do Sobrepeso e Obesidade, valendo-se das seguintes dimensões de análise: programas $e$ ações de prevenção e controle da obesidade, caracterização das macropolíticas segundo a tipologia de Lowi e caracterização das ações segundo princípios da Linha de Cuidado do Sobrepeso e Obesidade. O estudo é parte de uma pesquisa realizada entre 2014 e 2018 que teve como objetivo identificar as estratégias adotadas e os desafios enfrentados para consolidar as ações previstas na Linha de Cuidado do Sobrepeso e Obesidade, com base nos métodos de análise de dados secundários e documentos governamentais; busca nos sites oficiais dos municípios; entrevistas, grupos focais e questionários eletrônicos com profissionais e gestores de saúde. Os documentos apontam uma série de ações como a consulta individual, grupos de apoio, academia da saúde, programa saúde na escola, entre outros, que foram reforçadas pelas narrativas dos entrevistados. Mesmo diante de tantas iniciativas, os municípios do Estado do Rio de Janeiro passam por desafios como recursos humanos reduzidos e estrutura de unidades e equipamentos de saúde precários. Para que haja maior mobilização em relação às ações frente à obesidade, o tema deve ser tratado de forma particular nas agendas estaduais e municipais, e não dissolvido dentro de outras ações e programas.

Obesidade; Políticas Públicas; Atenção Primária à Saúde doi: 10.1590/0102-311X00116519

\author{
Correspondência \\ D. B. N. Ramos \\ Universidade Federal Fluminense. \\ Rua Mario Santos Braga 30, 4o andar, Niterói, RJ \\ 24020-140, Brasil. \\ doraliceuff@gmail.com

\footnotetext{
1 Universidade Federal Fluminense, Niterói, Brasil.

2 Universidade do Estado do Rio de Janeiro, Rio de Janeiro, Brasil.

3 Secretaria de Estado de Saúde do Rio de Janeiro, Rio de Janeiro, Brasil.

4 Universidade Federal do Estado do Rio de Janeiro, Rio de Janeiro, Brasil.

5 Instituto Estadual de Cardiologia Aloysio de Castro, Rio de Janeiro, Brasil.
} \\ ${ }^{6}$ Fundação Municipal de Saúde de Niterói, Niterói, Brasil.
}




\section{Introdução}

A obesidade é considerada prioridade de saúde pública e epidemia mundial de difícil reversão, dada a complexidade de seus condicionantes 1 . Nas capitais do Brasil, a obesidade aumentou 67,8\% em 13 anos em maiores de 18 anos (de 11,8\% em 2006 para 19,8\% em 2018) 2 e em 2013 o excesso de peso e a obesidade atingiram, respectivamente, $56,9 \%$ e $20,8 \%$ da população adulta brasileira 3 .

Essa prevalência vem sendo associada ao elevado consumo de ultraprocessados, ao sedentarismo e aos fatores genéticos que explicam uma parcela muito reduzida dos quadros de obesidade. No entanto, são múltiplos os condicionantes que contribuem para o atual perfil de práticas alimentares e de atividade física, incluindo questões biopsicossociais e culturais, acesso à informação, oferta e acesso à alimentação adequada e saudável, condições para realizar escolhas saudáveis, fatores relacionados ao sistema alimentar, dentre outros 1 .

Foi instituído no país, por meio das Política Nacional de Segurança Alimentar e Nutricional (PNSAN) e da Política Nacional de Promoção da Saúde, um conjunto de programas que potencialmente afetam um ou mais condicionantes da obesidade 4, e o Sistema Único de Saúde (SUS) desempenha atribuições estratégicas neste processo, tais como: promoção da alimentação e do peso saudável; diagnóstico precoce; procedimentos cirúrgicos e medicamentosos para os casos graves 1 . No entanto, um desafio é integrar as ações no âmbito da promoção da saúde, da prevenção e do tratamento de doenças crônicas não transmissíveis (DCNT) 5 .

A organização de Redes de Atenção à Saúde (RAS) no SUS prevê a formação de relações horizontais entre os pontos de atenção à saúde, tendo como centro de comunicação a atenção primária à saúde (APS) 6. Nesse contexto, foi instituída em 2013, a Linha de Cuidado do Sobrepeso e Obesidade como uma das linhas prioritárias da RAS das pessoas com doenças crônicas 7,8. A expectativa do Ministério da Saúde é que sejam construídas Linha de Cuidado do Sobrepeso e Obesidade regionais, considerando a oferta diferenciada de serviços entre municípios de uma mesma região e a integração das redes municipais, visando a promover um fluxo adequado de atendimento. Esse processo demanda conhecer as ações de enfrentamento da obesidade desenvolvidas nos municípios e identificar desafios e caminhos encontrados para implantá-las.

Os estudos de Dias et al. 4 e Henriques et al. ${ }^{9}$ analisaram as concepções sobre obesidade e as ações de prevenção e controle da obesidade infantil propostas nas "macropolíticas" nacionais. Em diálogo com essas pesquisas, este estudo tem como foco o contexto municipal e analisou as ações da APS realizadas nos municípios do Estado do Rio de Janeiro à luz das referências federais para a construção das Linha de Cuidado do Sobrepeso e Obesidade regionais, destacando desafios para a local.

\section{Métodos}

O estudo é parte de uma pesquisa que mapeou e analisou as ações de prevenção e controle da obesidade e sobrepeso nos 92 municípios do Estado do Rio de Janeiro entre 2014-2018, com base em diversos métodos e fontes de dados: (1) análise de dados secundários; (2) análise documental 10; (3) entrevistas semiestruturadas presenciais com apoiadores regionais da APS, referências regionais e coordenadoras municipais das Áreas Técnicas de Alimentação e Nutrição (ATAN); (4) grupos focais com referências municipais da ATAN e profissionais de saúde das nove regiões de saúde do Estado do Rio de Janeiro, apoiadores regionais da APS e interlocutores da vigilância de DCNT da Secretaria de Estado de Saúde; (5) aplicação de formulário on-line (FormSUS) e entrevistas telefônicas com referências municipais da ATAN (Quadros 1 e 2).

O conjunto de dados foi analisado de forma integrada com base em dimensões analíticas definidas, valendo-se dos objetivos do estudo de identificar e analisar as ações de prevenção e controle do sobrepeso e obesidade, desenvolvidas no Estado do Rio de Janeiro, à luz das referências federais para a construção da Linha de Cuidado do Sobrepeso e Obesidade. A análise baseou-se, por um lado, em referenciais teóricos que contribuem para caracterizar as macropolíticas e, por outro, em referenciais empíricos, formalizados nas normativas nacionais e estaduais, que induzem e orientam estados e municípios brasileiros na construção da Linha de Cuidado do Sobrepeso e Obesidade. 


\section{Quadro 1}

Síntese dos métodos de construção dos dados para a análise das ações de prevenção e controle do sobrepeso e obesidade nos municípios do Estado do Rio de Janeiro, Brasil, 2014-2018.

\begin{tabular}{|c|c|c|c|}
\hline & & Dados primários & Dados secundários \\
\hline \multirow[t]{4}{*}{$\begin{array}{l}\text { 1ạ etapa } \\
(2014-2016)\end{array}$} & $\begin{array}{c}\text { Entrevistas } \\
\text { semiestruturadas }\end{array}$ & $\begin{array}{c}\text { • } 5 \text { entrevistas com apoiadores regionais da APS; } \\
\text { • } 8 \text { entrevistas com referências regionais da ATAN; } \\
\text { - } 1 \text { referência de ATAN de município que iniciou processo } \\
\text { de implantação de ações de prevenção e controle da } \\
\text { obesidade na perspectiva da RAS. }\end{array}$ & \multirow{4}{*}{$\begin{array}{l}\text { Análise documental de políticas } \\
\text { nacionais, estaduais e municipais; } \\
\text { Análise de dados das nove regiões } \\
\text { de saúde do Estado do Rio de } \\
\text { Janeiro referentes aos indicadores } \\
\text { de saúde, de perfil alimentar } \\
\text { e nutricional da população, de } \\
\text { infraestrutura de gestão. }\end{array}$} \\
\hline & Grupos focais & $\begin{array}{l}\text { • } 55 \text { participantes, incluindo: } \\
\text { • referências municipais da ATAN; } \\
\text { • profissionais de saúde de nove regiões de saúde do } \\
\text { Estado do Rio de Janeiro. }\end{array}$ & \\
\hline & Formulário FormSUS & - 16 referências municipais da ATAN. & \\
\hline & Entrevistas telefônicas & - 20 referências municipais da ATAN. & \\
\hline \multirow{3}{*}{$\begin{array}{l}\text { 2a etapa } \\
(2016-2018)\end{array}$} & Roda de conversa & - Integrantes da ATAN estadual. & \multirow{3}{*}{$\begin{array}{l}\text { Análise documental de políticas } \\
\text { nacionais, estaduais e municipais; } \\
\text { Identificação de planos e ações } \\
\text { municipais por meio de busca } \\
\text { nos sites oficiais e na rede social } \\
\text { Facebook de todas as prefeituras } \\
\text { dos } 92 \text { municípios do Estado do } \\
\text { Rio de Janeiro. Foram encontradas } \\
\text { informações nos sites de } 50 \\
\text { municípios. }\end{array}$} \\
\hline & Grupos focais & $\begin{array}{c}\text { • } 8 \text { apoiadores regionais da APS; } \\
\text { • } 3 \text { grupos focais com interlocutores da vigilância de } \\
\text { doenças crônicas da SES do Rio de Janeiro (28 participantes } \\
\text { incluindo médicos, nutricionistas, psicólogos e enfermeiros } \\
\text { que atuam nos setores municipais de vigilância } \\
\text { epidemiológica, controle do tabagismo, hipertensão e } \\
\text { diabetes, ATAN, e nas unidades de saúde). }\end{array}$ & \\
\hline & Entrevistas & $\begin{array}{c}\text { • } 2 \text { referências de ATAN de municípios em processo de } \\
\text { construção de ações de prevenção e controle da obesidade } \\
\text { na perspectiva da RAS. }\end{array}$ & \\
\hline
\end{tabular}

APS: atenção primária à saúde; ATAN: Área Técnica de Alimentação e Nutrição; RAS: Rede de Atenção à Saúde; SES: Secretaria de Estado da Saúde.

Dessa forma, combinou: (1) os princípios que fundamentam a tipologia clássica de políticas formulada por Lowi ${ }^{10}$, que pressupõe que as diferentes características das macropolíticas (distributivas, redistributivas, regulatórias e constitutivas) expressam formas distintas do exercício da autoridade governamental e de influência no processo político. Portanto, podem incidir diretamente nas condutas individuais/de segmentos específicos ou nos contextos 10 e afetar de forma distinta uma dada situação, como a obesidade; (2) os princípios que fundamentam a RAS e a Linha de Cuidado do Sobrepeso e Obesidade que visam a garantir a integralidade do cuidado. Com base nos princípios da Linha de Cuidado do Sobrepeso e Obesidade as ações foram caracterizadas segundo: (a) os fatores condicionantes da obesidade que são potencialmente afetados por esses programas e ações (considerando que a Linha de Cuidado do Sobrepeso e Obesidade prevê como diretriz para organização da RAS o monitoramento dos "determinantes" da obesidade); (b) a relação com a promoção, prevenção e recuperação da saúde (considerando a possibilidade de atenção integral); (c) a regularidade da oferta (se pontual ou permanente) e o público atendido (considerando o princípio da universalidade); (d) a perspectiva multidisciplinar com base na caracterização dos profissionais envolvidos (considerando que a assistência terapêutica multiprofissional é preconizada pela Linha de Cuidado do Sobrepeso e Obesidade) (Quadro 2).

O escopo da análise referiu-se ao conjunto de programas e ações indicados nos documentos oficiais e desenvolvidos nos municípios, destacados pelos depoentes por seu impacto potencial no sobrepeso e na obesidade. Dentro dos limites do estudo não foi possível analisar em profundidade 
Quadro 2

Síntese das fontes de pesquisa, elementos empíricos identificados e dimensões de análise das ações de prevenção e controle do sobrepeso e obesidade nos municípios do Estado do Rio de Janeiro, Brasil, 2014-2018, segundo os métodos utilizados.

\begin{tabular}{|c|c|c|c|c|}
\hline \multirow[t]{2}{*}{ Métodos } & \multirow[t]{2}{*}{ Fontes } & \multicolumn{3}{|c|}{ Dimensões de análise } \\
\hline & & $\begin{array}{c}\text { Programas e ações de } \\
\text { prevenção e controle da } \\
\text { obesidade }\end{array}$ & \begin{tabular}{|c|} 
Caracterização \\
das macropolíticas \\
segundo a tipologia de \\
Lowi 10
\end{tabular} & $\begin{array}{l}\text { Caracterização das ações segundo } \\
\text { princípios da Linha de Cuidado do } \\
\text { Sobrepeso e Obesidade }\end{array}$ \\
\hline $\begin{array}{l}\text { Análise } \\
\text { documental }\end{array}$ & $\begin{array}{c}\text { Políticas nacionais, } \\
\text { estaduais e municipais } \\
1,6,7,8,11,12,13,15,16,17,21,22 \\
\text { e documentos que } \\
\text { subsidiam diretamente } \\
\text { a ação dos profissionais } \\
\text { que atendem na RAS, } \\
\text { especialmente os } \\
\text { Cadernos de Atenção } \\
\text { Básica relacionados ao } \\
\text { tema: }{ }^{\circ} 38 \text { 5, n } 12 \text { 18, } n^{\circ} \\
\text { 35 19 e o } n^{\circ} 27 \text { 20; } \\
\text { Principais Macropolíticas } \\
\text { do SUS: } \\
\text { Política Nacional de } \\
\text { Atenção Básica } 11 ; \text { Política } \\
\text { Nacional de Promoção } \\
\text { da Saúde } 14 ; \text { Plano de } \\
\text { Ações Estratégicas para o } \\
\text { Enfrentamento das DCNT } \\
\text { - 2013-2022 } 21\end{array}$ & $\begin{array}{l}\text { Organização da Linha de } \\
\text { Cuidado do Sobrepeso e } \\
\text { Obesidade na Rede de Atenção } \\
\text { às Pessoas com Doenças } \\
\text { Crônicas; Programa Saúde na } \\
\text { Escola; Programa Academia } \\
\text { da Saúde; Programa Crescer } \\
\text { Saudável; Vigilância Alimentar e } \\
\text { Nutricional; ações de promoção } \\
\text { da alimentação adequada e } \\
\text { saudável; ações de promoção da } \\
\text { atividade física; } \\
\text { regulação de publicidade } \\
\text { alimentar; acordos voluntários } \\
\text { para a redução de sódio nos } \\
\text { alimentos industrializados; } \\
\text { promoção da amamentação e } \\
\text { da alimentação complementar } \\
\text { adequada; ações de educação } \\
\text { alimentar e nutricional; } \\
\text { terapêutica nutricional por meio } \\
\text { do atendimento individual; } \\
\text { terapêutica multiprofissional } \\
\text { desenvolvida por meio de } \\
\text { equipe multidisciplinar e } \\
\text { cirurgia. }\end{array}$ & \begin{tabular}{|} 
Políticas constitutivas \\
que conformam \\
estruturas institucionais \\
indutoras de ações; \\
Políticas regulatórias \\
da publicidade e \\
comercialização de \\
alimentos.
\end{tabular} & $\begin{array}{c}\text { A relação das ações com a promoção, } \\
\text { prevenção e recuperação da saúde } \\
\text { (considerando a possibilidade de } \\
\text { atenção integral); } \\
\text { Os fatores condicionantes da obesidade } \\
\text { que são potencialmente afetados por } \\
\text { esses programas e ações (considerando } \\
\text { que a Linha de Cuidado do Sobrepeso } \\
\text { e Obesidade prevê como diretriz para a } \\
\text { organização da RAS o monitoramento } \\
\text { dos “determinantes” da obesidade); } \\
\text { A regularidade da oferta (se pontual } \\
\text { ou permanente) e o público atendido } \\
\text { (considerando o princípio da } \\
\text { universalidade); } \\
\text { A perspectiva multidisciplinar de } \\
\text { desenvolvimento das ações, com base } \\
\text { na caracterização dos profissionais } \\
\text { envolvidos (considerando que a } \\
\text { assistência terapêutica multiprofissional } \\
\text { preconizada pela Linha de Cuidado do } \\
\text { Sobrepeso e Obesidade). }\end{array}$ \\
\hline $\begin{array}{l}\text { Análise } \\
\text { de dados } \\
\text { secundários }\end{array}$ & $\begin{array}{c}\text { Sites oficiais e na rede } \\
\text { social Facebook de todas } \\
\text { as prefeituras dos } 92 \\
\text { municípios do Estado } \\
\text { do Rio de Janeiro, com } \\
\text { o objetivo de buscar } \\
\text { mais informações sobre } \\
\text { as ações vigentes nos } \\
\text { municípios e assim } \\
\text { dialogar de forma mais } \\
\text { concreta com os dados } \\
\text { empíricos. }\end{array}$ & $\begin{array}{l}\text { Programas e ações de estímulo } \\
\text { à pratica da atividade física } \\
\text { por meio de atividades ao ar } \\
\text { livre, palestras e orientações } \\
\text { por profissionais e centros } \\
\text { de tratamento da obesidade } \\
\text { e doenças crônicas não } \\
\text { transmissíveis. }\end{array}$ & $\begin{array}{c}\text { Ações que possam } \\
\text { oportunizar o debate } \\
\text { sobre políticas } \\
\text { constitutivas e } \\
\text { regulatórias vigentes } \\
\text { nos municípios. }\end{array}$ & $\begin{array}{l}\text { Propostas baseadas na perspectiva } \\
\text { multidisciplinar de desenvolvimento } \\
\text { das ações e assistência terapêutica } \\
\text { multiprofissional. }\end{array}$ \\
\hline
\end{tabular}

(continua) 


\begin{tabular}{|c|c|c|c|c|}
\hline \multirow[t]{2}{*}{ Métodos } & \multirow[t]{2}{*}{ Fontes } & \multicolumn{3}{|c|}{ Dimensões de análise } \\
\hline & & $\begin{array}{c}\text { Programas e ações de } \\
\text { prevenção e controle da } \\
\text { obesidade }\end{array}$ & $\begin{array}{c}\text { Caracterização } \\
\text { das macropolíticas } \\
\text { segundo a tipologia de } \\
\text { Lowi } 10\end{array}$ & $\begin{array}{l}\text { Caracterização das ações segundo } \\
\text { princípios da Linha de Cuidado do } \\
\text { Sobrepeso e Obesidade }\end{array}$ \\
\hline $\begin{array}{l}\text { Análise } \\
\text { de dados } \\
\text { primários }\end{array}$ & $\begin{array}{c}\text { Entrevistas } \\
\text { semiestruturadas, } \\
\text { grupos focais, } \\
\text { Formulário FormSUS e } \\
\text { entrevistas telefônicas. }\end{array}$ & $\begin{array}{l}\text { Atendimento individual, } \\
\text { atividades em grupo, cirurgia } \\
\text { bariátrica, Programa Saúde na } \\
\text { Escola, Programa Academia } \\
\text { da Saúde, campanhas } \\
\text { educativas, oficinas culinárias, } \\
\text { centros de tratamento da } \\
\text { obesidade e doenças crônicas } \\
\text { não transmissíveis, ações de } \\
\text { promoção da alimentação } \\
\text { saudável nas escolas, ações de } \\
\text { regulação da publicidade de } \\
\text { alimentos infantis e vigilância } \\
\text { alimentar e nutricional. }\end{array}$ & $\begin{array}{l}\text { Os depoentes destacam } \\
\text { a relevância das } \\
\text { ações regulatórias } \\
\text { para a prevenção e } \\
\text { controle da obesidade, } \\
\text { especialmente } \\
\text { regulação da } \\
\text { publicidade de } \\
\text { alimentos infantis } \\
\text { e regulação da } \\
\text { alimentação oferecida } \\
\text { nas escolas. Associam } \\
\text { tais ações com } \\
\text { a perspectiva de } \\
\text { promover mudanças } \\
\text { nos condicionantes } \\
\text { ambientais da } \\
\text { obesidade. }\end{array}$ & $\begin{array}{l}\text { Os depoentes destacam a importância } \\
\text { da articulação intra e intersetorial no } \\
\text { âmbito da gestão como estratégica para } \\
\text { a atenção integral em saúde, além da } \\
\text { equipe multiprofissional; } \\
\text { Os principais fatores condicionantes da } \\
\text { obesidade destacados referem-se: ao } \\
\text { acesso à informação sobre alimentação } \\
\text { adequada, especialmente por meio } \\
\text { do atendimento individual, em grupo } \\
\text { e campanhas educativas; ao estímulo } \\
\text { ao preparo adequado dos alimentos } \\
\text { por meio das oficinas culinárias; à } \\
\text { regulação da oferta e dos mecanismos } \\
\text { de incentivo ao consumo, especialmente } \\
\text { publicidade de alimentos infantis e } \\
\text { alimentação escolar; } \\
\text { Especialmente as entrevistas e grupos } \\
\text { focais integrados por profissionais que } \\
\text { atuam na rede de atenção à saúde } \\
\text { destacaram de forma significativa } \\
\text { os condicionantes psicológicos da }\end{array}$ \\
\hline
\end{tabular}

DCNT: doenças crônicas não transmissíveis; RAS: Rede de Atenção à Saúde; SUS: Sistema Único de Saúde.

o processo de operacionalização local, em cada município do Estado do Rio de Janeiro, de nenhum programa específico. O projeto de pesquisa foi financiado por meio do Edital PPSUS $\backslash$ FAPERJ - E $26 \backslash 110.293 \backslash 2014$ e aprovado pelo Comitê de Ética do Hospital Antônio Pedro - Parecer CEP 508.687 de 09/01/2014 - CAAE 22822413.0.0000.5243.

\section{Resultados e discussão}

\section{Macropolíticas indutoras de ações de prevenção e controle do sobrepeso e obesidade nos municípios}

A indicação de ações e responsabilidades dos diferentes níveis de gestão por meio de políticas e normativas governamentais contribui para induzir e orientar dinâmicas locais. Nesse sentido, a atual Política Nacional da Atenção Básica 11, assim como as anteriores 12,13, estabelece que a Estratégia Saúde da Família (ESF) é prioritária para a expansão e consolidação da APS, e a gestão municipal é responsável por criar condições para que a APS realize a organização do fluxo de atendimento visando a garantir a integralidade do cuidado. Portanto, excetuando os procedimentos cirúrgicos, cabe à APS 
toda a estrutura de atenção e cuidado do indivíduo com sobrepeso e obesidade, inclusive a assistência pós-cirúrgica. Nessa política destacam-se dois programas com potencial impacto na obesidade: o Programa Saúde na Escola (PSE) e o Programa Academia da Saúde 13. Além desses, a Política Nacional de Promoção da Saúde pode ser considerada como potencialmente indutora de ações de prevenção e controle da obesidade porque estabelece como temas prioritários: (a) o desenvolvimento das ações de Promoção da Alimentação Adequada e Saudável (PAAS); (b) a promoção da segurança alimentar e nutricional, visando a contribuir com a garantia do Direito Humano à Alimentação Adequada; (c) o incentivo às práticas corporais e de atividade física, oportunizando espaços públicos para possibilitar atividades corporais que potencializam a atenção integral à saúde 14 .

As normativas federais podem induzir dinâmicas municipais ao indicarem ações, estabelecerem diretrizes e recursos para a implantação, e nortearem a organização da RAS 6 visando à assistência integral às pessoas com doenças crônicas 15 , sobrepeso e obesidade 7,8,16. O manual instrutivo para a organização regional da Linha de Cuidado do Sobrepeso e Obesidade 17 subsidia os gestores responsáveis pelo planejamento governamental nos estados, municípios e nas regiões de saúde, e os Cadernos de Atenção Básica 5,18,19,20 propõem ações específicas que visam a subsidiar a atuação dos profissionais na RAS.

Dentre as ações específicas destacam-se a vigilância alimentar e nutricional; ações de promoção da saúde e prevenção da obesidade em perspectiva intersetorial, com ênfase na PAAS e na atividade física; estratégias regulatórias de mídia e rotulagem; políticas de segurança pública (para a prática de atividade física); apoio ao autocuidado; ações de promoção da amamentação e da alimentação complementar adequada; Iniciativas Hospital Amigo da Criança e Unidade Básica Amiga da Amamentação (IUBAAM); ações de educação alimentar e nutricional; avaliação e educação nutricional por meio de programas intersetoriais como o PSE e o Programa Bolsa Família; atividades educativas em grupo; atendimento individual, incluindo assistência terapêutica multiprofissional aos usuários que realizaram procedimento cirúrgico; resgate das práticas culinárias e garantia do acolhimento adequado às pessoas com obesidade em todos os equipamentos da APS.

O Cadernos de Atenção Básica 385 aprofunda a perspectiva matricial e interdisciplinar de cuidado, especialmente por meio dos Núcleos de Apoio à Saúde da Família (NASF) e equipes multiprofissionais, e ressalta que o controle da obesidade demanda um escopo amplo de ações que integrem incentivo, apoio e proteção às práticas saudáveis de alimentação e atividade física.

No contexto do Estado do Rio de Janeiro, o Plano de Ações Estratégicas para o Enfrentamento das DCNT - 2013-2022 21, elaborado em sintonia com o nacional 22, constitui um mecanismo potencial de indução para o planejamento local, por ser o único que prevê metas e indicadores especificamente relacionados com a obesidade (manutenção da prevalência de 49,6\% de excesso de peso e de 16,5\% de obesidade em adultos). As ações propostas incluem: estimular o hábito de práticas corporais/atividade física no cotidiano e no curso da vida; apoiar iniciativas intersetoriais para a promoção de modos de vida saudáveis nos territórios, considerando espaços urbanos (escola, ambiente de trabalho, equipamentos públicos de alimentação e nutrição, atividade física e redes de saúde e socioassistencial) e espaços rurais (unidades de conservação e parques nacionais); e estruturar e implantar modelos de atenção integral à saúde do portador de excesso de peso/obesidade na rede de saúde, em especial na APS 21.

Tais macropolíticas do SUS se aproximam do que Lowi 10 classifica como políticas constitutivas, pois contribuem para instituir os próprios espaços, ferramentas, protocolos e processos que conformam uma dada estrutura institucional indutora dos programas e ações. Também operam como políticas redistributivas, pois, apesar de universais, atendem a segmentos da sociedade com menor acesso a bens e serviços públicos. Outras macropolíticas, especialmente as regulatórias e acordos voluntários com a indústria alimentícia para alterar a composição de seus produtos, são atribuições da esfera federal ${ }^{9}$. No entanto, a regulação do ambiente alimentar de escolas integra iniciativas estaduais e municipais. 


\section{Ações de prevenção e controle do sobrepeso e obesidade desenvolvidas nos municípios do Estado do Rio de Janeiro}

Os relatos dos coordenadores e ATAN municipais foram os mais específicos e informativos sobre as ações realizadas, entre elas, o atendimento individual, as atividades em grupo e a cirurgia bariátrica. Apesar de destacarem um conjunto amplo e diversificado de iniciativas, consideram que as ações de assistência e recuperação do quadro de obesidade são as que integram de forma sistemática seu cotidiano de trabalho, inclusive diante de um diagnóstico tardio. A vigilância alimentar e nutricional não é tão valorizada como instrumento de planejamento e gestão, mesmo nas ATAN, e a análise dos dados sobre o estado nutricional é frágil na rotina dos serviços em alguns municípios, exemplificado no relato de uma referência regional: "Na região, os dados do SISVAN são pouco utilizados pelos municípios que fazem o consumo alimentar (...) se a gente pudesse ter uma vigilância mais apurada seria o ideal para pensar em políticas públicas a nível regional, municipal, mas é um dado pouco levantado".

As diversas ações abordadas pelos informantes foram: a consulta individual, grupos educativos voltados para indivíduos com sobrepeso e obesidade, campanhas para a população em geral e ações de educação alimentar e nutricional para usuários do Programa Bolsa Família, desenvolvidas em parceria com o NASF, ou no âmbito dos programas de combate à hipertensão e diabetes, grupos de caminhadas, atividades de salas de espera e ações de promoção do aleitamento materno. As campanhas e ações de educação alimentar e nutricional consistem principalmente em "palestras" e "debates". A escola foi recorrentemente identificada como espaço estratégico para as ações de PAAS, educação alimentar e nutricional, regulação de cantinas, publicidade de alimentos e hortas. O programa mais referido foi o PSE, que prevê ações educativas e avaliação antropométrica, privilegiado na maioria dos municípios.

No entanto, essas ações ocorrem de forma pontual durante o ano, especialmente na Semana Saúde na Escola, que tem pautado de forma recorrente o tema da obesidade 23 . Destaca-se o Programa Crescer Saudável, voltado para a prevenção e controle da obesidade infantil no âmbito do PSE, que prevê ações de avaliação nutricional, PAAS, promoção de práticas corporais e encaminhamento dos casos de obesidade para a RAS.

Em geral os municípios implantam ações e programas que são induzidos pelo Governo Federal com financiamento específico, como a PAAS, PSE, o Programa Crescer Saudável e o Programa Academia da Saúde, cujas ações são financiadas pelo Piso de Atenção Básica (Quadro 3). No entanto, algumas iniciativas específicas da gestão municipal foram identificadas conforme apresentado no Quadro 4.

No que se refere aos grupos populacionais atendidos, o PSE é um programa do SUS direcionado exclusivamente para escolares, que propõe a articulação da APS com as secretarias de educação dos municípios, oferecendo apoio no mapeamento do estado nutricional deste grupo. Além disso, o Programa Crescer Saudável, que opera no âmbito do PSE, prevê em seu desenho operacional o incentivo à integração entre as equipes das escolas e da saúde, incluindo os profissionais que compõem os NASF, para a execução das ações sugeridas pelo programa, relacionadas à alimentação saudável, atividade física, ao apoio psicológico, entre outros 24. O grupo infantil é assistido por meio desses programas e, pela IUBAAM e a Estratégia Amamenta e Alimenta Brasil que visam à promoção do aleitamento materno e a alimentação complementar oportuna. Diversas ações são voltadas para o atendimento dos adultos, tais como consultas individuais, grupos educativos, Programa Academia da Saúde e ações de educação alimentar e nutricional relacionadas com obesidade e DCNT.

O Programa Academia da Saúde foi destacado, tanto nas propostas governamentais analisadas quanto pelos interlocutores e profissionais da APS, pelos possíveis impactos na prevenção e controle da obesidade, pois afeta múltiplos condicionantes (Quadro 3). Os gestores e profissionais das ATAN não relataram uma vivência mais próxima ao cotidiano de operacionalização do programa, ainda que reconheçam sua importância. Trata-se de um equipamento público que possibilita um local seguro e adequado para práticas corporais integradas à PAAS, e vem sendo considerado um componente estratégico da APS no que se refere à integração das linhas de cuidado e articulação dos cuidados individuais e coletivos $1,5,17,21$.

Cavalcante 25 reitera essa perspectiva ao analisar o enfrentamento do sobrepeso e da obesidade no Município do Rio de Janeiro e indica que as Academias Cariocas da Saúde potencializam a articulação com os serviços de saúde, possibilitando parcerias entre as coordenações e áreas técnicas. Segundo 
Quadro 3

Programas e ações do Governo Federal com potencial impacto na prevenção e controle do sobrepeso e obesidade operacionalizados nos municípios do Estado do Rio de Janeiro, Brasil, 2014-2018.

\begin{tabular}{|c|c|c|c|c|c|}
\hline \multirow{2}{*}{$\begin{array}{l}\text { Programa/ } \\
\text { Estratégia/Ação }\end{array}$} & \multirow[t]{2}{*}{ Atividades propostas } & \multicolumn{4}{|c|}{ Características das ações } \\
\hline & & $\begin{array}{l}\text { Determinantes } \\
\text { da obesidade } \\
\text { que podem ser } \\
\text { afetados }\end{array}$ & $\begin{array}{c}\text { Foco da ação sobre } \\
\text { condutas individuais ou } \\
\text { sobre o ambiente }\end{array}$ & $\begin{array}{l}\text { Regularidade e } \\
\text { público atendido }\end{array}$ & $\begin{array}{l}\text { Profissionais } \\
\text { envolvidos }\end{array}$ \\
\hline $\begin{array}{l}\text { Programa Saúde na } \\
\text { Escola }\end{array}$ & $\begin{array}{c}\text { Avaliação } \\
\text { antropométrica, } \\
\text { promoção de } \\
\text { atividade física, } \\
\text { educação alimentar e } \\
\text { nutricional e atividade } \\
\text { de educação em } \\
\text { saúde. }\end{array}$ & $\begin{array}{c}\text { Acesso às } \\
\text { informações em } \\
\text { saúde/alimentação } \\
\text { saudável; } \\
\text { acesso à assistência } \\
\text { em saúde. }\end{array}$ & $\begin{array}{l}\text { Condutas de segmentos } \\
\text { específicos (escolares). }\end{array}$ & $\begin{array}{l}\text { Frequente. } \\
\text { Escolares. }\end{array}$ & $\begin{array}{c}\text { Profissionais de } \\
\text { saúde e educação. }\end{array}$ \\
\hline $\begin{array}{l}\text { Estratégia Saúde da } \\
\text { Família }\end{array}$ & $\begin{array}{l}\text { Atendimento clínico } \\
\text { e orientações sobre } \\
\text { saúde e nutrição. }\end{array}$ & $\begin{array}{c}\text { Acesso às } \\
\text { informações em } \\
\text { saúde/alimentação } \\
\text { saudável; } \\
\text { acesso à assistência } \\
\text { em saúde. }\end{array}$ & $\begin{array}{c}\text { Condutas de segmentos } \\
\text { específicos (famílias } \\
\text { atendidas). }\end{array}$ & $\begin{array}{l}\text { Frequente. } \\
\text { População. }\end{array}$ & $\begin{array}{l}\text { Profissionais de } \\
\text { saúde e agentes } \\
\text { comunitários de } \\
\text { saúde. }\end{array}$ \\
\hline $\begin{array}{l}\text { Promoção do } \\
\text { aleitamento materno }\end{array}$ & $\begin{array}{c}\text { Ações de promoção } \\
\text { do aleitamento } \\
\text { materno, como a } \\
\text { Iniciativa Hospital } \\
\text { Amigo da Criança, } \\
\text { Rede Amamenta } \\
\text { Brasil, Estratégia } \\
\text { Nacional de Promoção } \\
\text { da Alimentação } \\
\text { Complementar } \\
\text { Saudável para } \\
\text { crianças menores de } \\
2 \text { anos de idade e a } \\
\text { Estratégia Amamenta } \\
\text { e Alimenta Brasil. }\end{array}$ & $\begin{array}{c}\text { Acesso às } \\
\text { informações em } \\
\text { saúde/alimenta-ção } \\
\text { saudável; } \\
\text { acesso à assistência } \\
\text { em saúde; } \\
\text { apoio às práticas de } \\
\text { saúde. }\end{array}$ & $\begin{array}{l}\text { Condutas de segmentos } \\
\text { específicos (nutrizes). }\end{array}$ & $\begin{array}{c}\text { Frequente } \\
\text { Crianças de } 0 \text { a } 2 \\
\text { anos. }\end{array}$ & $\begin{array}{l}\text { Profissionais de } \\
\text { saúde. }\end{array}$ \\
\hline $\begin{array}{l}\text { Programa de diabetes } \\
\text { e hipertensão }\end{array}$ & $\begin{array}{c}\text { Consultas e } \\
\text { atividades em grupo } \\
\text { para controlar e } \\
\text { monitorar o perfil } \\
\text { epidemiológico da } \\
\text { hipertensão arterial e } \\
\text { do diabetes mellitus } \\
\text { na população. }\end{array}$ & $\begin{array}{l}\text { Práticas alimentares } \\
\text { inadequadas; } \\
\text { sedentarismo. }\end{array}$ & $\begin{array}{l}\text { Condutas de segmentos } \\
\text { específicos (hipertensos } \\
\text { e diabéticos). }\end{array}$ & $\begin{array}{l}\text { Frequente. } \\
\text { Usuários do SUS com } \\
\text { hipertensão arterial } \\
\text { e/ou com diabetes. }\end{array}$ & $\begin{array}{l}\text { Profissionais de } \\
\text { saúde. }\end{array}$ \\
\hline $\begin{array}{l}\text { Programa Academia } \\
\text { da Saúde }\end{array}$ & $\begin{array}{l}\text { Práticas corporais, } \\
\text { atividade física } \\
\text { e promoção da } \\
\text { alimentação saudável. }\end{array}$ & $\begin{array}{l}\text { Sociabilidade; } \\
\text { práticas corporais; } \\
\text { informações em } \\
\text { saúde. }\end{array}$ & $\begin{array}{l}\text { Ambiente e contexto } \\
\text { alterados para ofertar } \\
\text { locais adequados e } \\
\text { estimular a prática de } \\
\text { atividade física. }\end{array}$ & $\begin{array}{c}\text { Frequente. } \\
\text { Usuários do SUS. }\end{array}$ & $\begin{array}{l}\text { Profissionais da } \\
\text { saúde. }\end{array}$ \\
\hline
\end{tabular}

(continua) 
Quadro 3 (continuação)

\begin{tabular}{|c|c|c|c|c|c|}
\hline \multirow{2}{*}{$\begin{array}{l}\text { Programa/ } \\
\text { Estratégia/Ação }\end{array}$} & \multirow[t]{2}{*}{ Atividades propostas } & \multicolumn{4}{|c|}{ Características das ações } \\
\hline & & $\begin{array}{l}\text { Determinantes } \\
\text { da obesidade } \\
\text { que podem ser } \\
\text { afetados }\end{array}$ & $\begin{array}{c}\text { Foco da ação sobre } \\
\text { condutas individuais ou } \\
\text { sobre o ambiente }\end{array}$ & $\begin{array}{l}\text { Regularidade e } \\
\text { público atendido }\end{array}$ & $\begin{array}{l}\text { Profissionais } \\
\text { envolvidos }\end{array}$ \\
\hline $\begin{array}{l}\text { Vigilância alimentar e } \\
\text { nutricional }\end{array}$ & $\begin{array}{l}\text { Monitoramento do } \\
\text { perfil alimentar e } \\
\text { nutricional. }\end{array}$ & $\begin{array}{c}\text { Acesso à } \\
\text { informação sobre } \\
\text { o perfil alimentar } \\
\text { e nutricional como } \\
\text { dado importante } \\
\text { para o planejamento } \\
\text { de ações e cuidado } \\
\text { em saúde. }\end{array}$ & Ambiente. & $\begin{array}{c}\text { Integrada à rotina do } \\
\text { serviço. }\end{array}$ & $\begin{array}{c}\text { Profissionais de } \\
\text { saúde. }\end{array}$ \\
\hline
\end{tabular}

SUS: Sistema Único de Saúde.

\section{Quadro 4}

Programas e ações de iniciativa municipal com potencial impacto na prevenção e controle do sobrepeso e obesidade desenvolvidos nos municípios do Estado do Rio de Janeiro, Brasil, 2014-2018.

\begin{tabular}{|c|c|c|c|c|c|}
\hline \multirow{2}{*}{$\begin{array}{l}\text { Programa/Ação } \\
\text { (município) }\end{array}$} & \multirow[t]{2}{*}{ Atividades desenvolvidas } & \multicolumn{4}{|c|}{ Características das ações } \\
\hline & & $\begin{array}{c}\text { Determinantes } \\
\text { da obesidade } \\
\text { que podem ser } \\
\text { afetados }\end{array}$ & $\begin{array}{l}\text { Foco da ação sobre } \\
\text { condutas individuais ou } \\
\text { sobre o ambiente }\end{array}$ & $\begin{array}{c}\text { Regularidade e } \\
\text { público atendido }\end{array}$ & $\begin{array}{c}\text { Profissionais } \\
\text { envolvidos }\end{array}$ \\
\hline $\begin{array}{l}\text { Blitz da Saúde } \\
\text { (Bom Jardim) }\end{array}$ & $\begin{array}{l}\text { Medida da pressão arterial e } \\
\text { da taxa de glicose; } \\
\text { orientações sobre o índice de } \\
\text { massa corpórea. }\end{array}$ & $\begin{array}{l}\text { Práticas } \\
\text { alimentares } \\
\text { inadequadas. }\end{array}$ & $\begin{array}{c}\text { Condutas de segmentos } \\
\text { específicos (que participam } \\
\text { das ações). }\end{array}$ & $\begin{array}{c}\text { Ação anual. } \\
\text { Toda população. }\end{array}$ & $\begin{array}{c}\text { Profissionais de } \\
\text { saúde e estudantes } \\
\text { de Enfermagem, } \\
\text { Nutrição, Odontologia } \\
\text { e Medicina. }\end{array}$ \\
\hline $\begin{array}{l}\text { Rua de Lazer } \\
\text { Especial na Vila } \\
\text { (Volta Redonda) }\end{array}$ & $\begin{array}{c}\text { Atividade física ao ar livre, } \\
\text { para prevenção da obesidade. } \\
\text { Palestras e bate papo sobre } \\
\text { saúde e orientações sobre } \\
\text { locais de atendimento. }\end{array}$ & $\begin{array}{l}\text { Práticas } \\
\text { alimentares } \\
\text { inadequadas; } \\
\text { sedentarismo. }\end{array}$ & $\begin{array}{c}\text { Condutas de segmentos } \\
\text { específicos (que participam } \\
\text { das ações). }\end{array}$ & $\begin{array}{l}\text { Ação pontual. } \\
\text { Toda população. }\end{array}$ & $\begin{array}{l}\text { Não há informação } \\
\text { sobre os profissionais } \\
\text { envolvidos. }\end{array}$ \\
\hline $\begin{array}{l}\text { Dia do Desafio } \\
\text { (Mangaratiba, } \\
\text { Quatis e Maricá) }\end{array}$ & $\begin{array}{l}\text { Passeios ciclísticos da } \\
\text { comunidade que visam } \\
\text { a incentivar a prática de } \\
\text { atividade física. }\end{array}$ & Sedentarismo. & $\begin{array}{c}\text { Condutas de segmentos } \\
\text { específicos (que participam } \\
\text { das ações). }\end{array}$ & $\begin{array}{c}\text { Ação anual. } \\
\text { Toda população. }\end{array}$ & $\begin{array}{l}\text { Não há informação } \\
\text { sobre os profissionais } \\
\text { envolvidos. }\end{array}$ \\
\hline $\begin{array}{l}\text { Projeto } \\
\text { Qualidade de } \\
\text { Vida } \\
\text { (Piraí e Volta } \\
\text { Redonda) }\end{array}$ & $\begin{array}{l}\text { Incentivo à atividade física } \\
\text { e orientações periódicas } \\
\text { com profissionais da área de } \\
\text { saúde. }\end{array}$ & $\begin{array}{l}\text { Sedentarismo; } \\
\text { práticas } \\
\text { alimentares } \\
\text { inadequadas. }\end{array}$ & $\begin{array}{c}\text { Condutas de segmentos } \\
\text { específicos (que participam } \\
\text { das ações). }\end{array}$ & $\begin{array}{c}\text { Frequente. } \\
\text { Usuários do SuS } \\
\text { com atestado } \\
\text { médico de aptidão } \\
\text { para atividades } \\
\text { físicas. }\end{array}$ & $\begin{array}{l}\text { Profissionais de } \\
\text { saúde. }\end{array}$ \\
\hline
\end{tabular}

(continua) 
Quadro 4 (continuação)

\begin{tabular}{|c|c|c|c|c|c|}
\hline \multirow{2}{*}{$\begin{array}{l}\text { Programa/Ação } \\
\text { (município) }\end{array}$} & \multirow[t]{2}{*}{ Atividades desenvolvidas } & \multicolumn{4}{|c|}{ Características das ações } \\
\hline & & $\begin{array}{l}\text { Determinantes } \\
\text { da obesidade } \\
\text { que podem ser } \\
\text { afetados }\end{array}$ & $\begin{array}{l}\text { Foco da ação sobre } \\
\text { condutas individuais ou } \\
\text { sobre o ambiente }\end{array}$ & $\begin{array}{l}\text { Regularidade e } \\
\text { público atendido }\end{array}$ & $\begin{array}{c}\text { Profissionais } \\
\text { envolvidos }\end{array}$ \\
\hline $\begin{array}{l}\text { Programa } \\
\text { Academia } \\
\text { Carioca } \\
\text { (Rio de Janeiro) }\end{array}$ & $\begin{array}{c}\text { Inserção da prática de } \\
\text { atividade física regular nas } \\
\text { UBS; } \\
\text { atividade física e educativa em } \\
\text { saúde, e visitas domiciliares, } \\
\text { com ações que auxiliam no } \\
\text { controle da pressão arterial e } \\
\text { na perda de peso. }\end{array}$ & $\begin{array}{l}\text { Sedentarismo; } \\
\text { práticas } \\
\text { alimentares } \\
\text { inadequadas. }\end{array}$ & $\begin{array}{c}\text { Condutas de segmentos } \\
\text { específicos (que participam } \\
\text { das ações); } \\
\text { Ambiente e contexto } \\
\text { alterado para ofertar locais } \\
\text { adequados para prática de } \\
\text { atividade física. }\end{array}$ & $\begin{array}{c}\text { Frequente. } \\
\text { Usuários do SUS } \\
\text { que apresentam } \\
\text { DCNT. }\end{array}$ & $\begin{array}{l}\text { Profissionais da } \\
\text { Educação Física. }\end{array}$ \\
\hline $\begin{array}{l}\text { Centro de } \\
\text { Referência em } \\
\text { Obesidade } \\
\text { (Rio de Janeiro) }\end{array}$ & $\begin{array}{l}\text { Atendimento ambulatorial } \\
\text { especializado de } \\
\text { acompanhamento de } \\
\text { indivíduos com obesidade } \\
\text { grau III. }\end{array}$ & $\begin{array}{c}\text { Práticas } \\
\text { alimentares } \\
\text { inadequadas; } \\
\text { sedentarismo. }\end{array}$ & Condutas individuais. & $\begin{array}{c}\text { Frequente. } \\
\text { Usuários do } \\
\text { SUS inseridos } \\
\text { em unidades de } \\
\text { Clínicas de Saúde } \\
\text { de Família. }\end{array}$ & $\begin{array}{l}\text { Profissionais de } \\
\text { saúde. }\end{array}$ \\
\hline $\begin{array}{l}\text { Projeto } \\
\text { Coma Bem, } \\
\text { Viva Melhor } \\
\text { (Petrópolis) }\end{array}$ & $\begin{array}{c}\text { Orientação multiprofissional } \\
\text { sobre alimentação saudável e } \\
\text { temas relacionados à saúde; } \\
\text { aferição de peso e da pressão } \\
\text { arterial. }\end{array}$ & $\begin{array}{c}\text { Práticas } \\
\text { alimentares } \\
\text { inadequadas; } \\
\text { sedentarismo. }\end{array}$ & $\begin{array}{c}\text { Condutas de segmentos } \\
\text { específicos (que participam } \\
\text { das ações). }\end{array}$ & $\begin{array}{c}\text { Frequente. } \\
\text { Usuários do SUS } \\
\text { inseridos em UBS. }\end{array}$ & $\begin{array}{l}\text { Profissionais de } \\
\text { saúde. }\end{array}$ \\
\hline $\begin{array}{l}\text { Grupo COPPA } \\
\text { (Controle da } \\
\text { obesidade e } \\
\text { Prevenção } \\
\text { de Patologias } \\
\text { Associadas) } \\
\text { (Petrópolis) }\end{array}$ & $\begin{array}{l}\text { Atividades em grupo } \\
\text { como oficinas de culinária, } \\
\text { caminhadas e aula de dança } \\
\text { para estimular a perda de } \\
\text { peso. }\end{array}$ & $\begin{array}{c}\text { Práticas } \\
\text { alimentares } \\
\text { inadequadas; } \\
\text { falta do apoio } \\
\text { à realização } \\
\text { de práticas de } \\
\text { preparo da } \\
\text { alimentação e } \\
\text { atividade física; } \\
\text { sedentarismo. }\end{array}$ & $\begin{array}{c}\text { Condutas de segmentos } \\
\text { específicos (que participam } \\
\text { das ações). }\end{array}$ & $\begin{array}{c}\text { Frequente. } \\
\text { Toda população. }\end{array}$ & $\begin{array}{l}\text { Profissionais } \\
\text { da Nutrição, } \\
\text { Enfermagem e } \\
\text { Administração. }\end{array}$ \\
\hline $\begin{array}{l}\text { Saber Saúde } \\
\text { (Itaguaí) }\end{array}$ & $\begin{array}{c}\text { Atividades sobre alimentação } \\
\text { inadequada e prevenção à } \\
\text { obesidade infantil e hábitos } \\
\text { saudáveis. }\end{array}$ & $\begin{array}{l}\text { Hábitos } \\
\text { inadequados de } \\
\text { alimentação dos } \\
\text { escolares, além do } \\
\text { estado nutricional. }\end{array}$ & $\begin{array}{c}\text { Condutas de segmentos } \\
\text { específicos (que participam } \\
\text { das ações). }\end{array}$ & $\begin{array}{l}\text { Frequente. } \\
\text { Crianças. }\end{array}$ & $\begin{array}{l}\text { Profissional da } \\
\text { Nutrição. }\end{array}$ \\
\hline $\begin{array}{l}\text { Casa do } \\
\text { Diabético e } \\
\text { Hipertenso } \\
\text { (Casa DIAH) } \\
\text { (Cachoeiras de } \\
\text { Macacu) }\end{array}$ & $\begin{array}{c}\text { Atendimento ambulatorial } \\
\text { com equipe multiprofissional } \\
\text { sobre alimentação saudável } \\
\text { e temas relacionados à saúde } \\
\text { e DCNT. }\end{array}$ & $\begin{array}{c}\text { Práticas } \\
\text { alimentares } \\
\text { inadequadas; } \\
\text { falta de apoio } \\
\text { à realização } \\
\text { de práticas de } \\
\text { preparo da } \\
\text { alimentação. }\end{array}$ & Condutas individuais. & $\begin{array}{l}\text { Frequente. } \\
\text { Usuários do SUS } \\
\text { inseridos em UBS } \\
\text { e de Clínicas de } \\
\text { Saúde da Família. }\end{array}$ & $\begin{array}{c}\text { Clínico geral, } \\
\text { nutricionista, } \\
\text { enfermeiro, técnicos } \\
\text { de enfermagem, } \\
\text { assistente } \\
\text { social, psicólogo, } \\
\text { farmacêutico e } \\
\text { fisioterapeuta. }\end{array}$ \\
\hline
\end{tabular}

(continua) 


\begin{tabular}{|c|c|c|c|c|c|}
\hline \multirow{2}{*}{$\begin{array}{l}\text { Programa/Ação } \\
\text { (município) }\end{array}$} & \multirow[t]{2}{*}{ Atividades desenvolvidas } & \multicolumn{4}{|c|}{ Características das ações } \\
\hline & & $\begin{array}{c}\text { Determinantes } \\
\text { da obesidade } \\
\text { que podem ser } \\
\text { afetados }\end{array}$ & $\begin{array}{c}\text { Foco da ação sobre } \\
\text { condutas individuais ou } \\
\text { sobre o ambiente }\end{array}$ & $\begin{array}{l}\text { Regularidade e } \\
\text { público atendido }\end{array}$ & $\begin{array}{c}\text { Profissionais } \\
\text { envolvidos }\end{array}$ \\
\hline $\begin{array}{l}\text { Centro de } \\
\text { Tratamento de } \\
\text { Hipertensão e } \\
\text { Diabetes (Cethid) } \\
\text { (Queimados) }\end{array}$ & $\begin{array}{c}\text { Atendimento ambulatorial } \\
\text { com equipe multiprofissional } \\
\text { sobre alimentação saudável } \\
\text { e temas relacionados à saúde } \\
\text { e DCNT. }\end{array}$ & $\begin{array}{c}\text { Práticas } \\
\text { alimentares } \\
\text { inadequadas; } \\
\text { falta de apoio } \\
\text { à realização } \\
\text { de práticas de } \\
\text { preparo da } \\
\text { alimentação. }\end{array}$ & Condutas individuais. & $\begin{array}{l}\text { Frequente. } \\
\text { Usuários do SUS } \\
\text { encaminhados } \\
\text { pelas UBS e } \\
\text { Estratégia Saúde } \\
\text { da Família. }\end{array}$ & $\begin{array}{c}\text { Clínico geral, } \\
\text { cardiologista, } \\
\text { fisioterapeuta, } \\
\text { endocrinologista, } \\
\text { angiologista, } \\
\text { oftalmologista, } \\
\text { enfermeiro, } \\
\text { nutricionista, } \\
\text { assistente social e } \\
\text { farmacêutico. }\end{array}$ \\
\hline $\begin{array}{l}\text { Centro de } \\
\text { Atendimento } \\
\text { em Doenças } \\
\text { Crônicas Não } \\
\text { Transmissíveis } \\
\text { (Barra Mansa) }\end{array}$ & $\begin{array}{c}\text { Apresentação de novos } \\
\text { alimentos de forma lúdica } \\
\text { e criativa, para que a } \\
\text { alimentação saudável se torne } \\
\text { uma rotina e não só parte do } \\
\text { tratamento para emagrecer. }\end{array}$ & $\begin{array}{c}\text { Práticas } \\
\text { alimentares } \\
\text { inadequadas; } \\
\text { falta de apoio } \\
\text { à realização } \\
\text { de práticas de } \\
\text { preparo da } \\
\text { alimentação; } \\
\text { sedentarismo. }\end{array}$ & $\begin{array}{c}\text { Condutas de segmentos } \\
\text { específicos (que participam } \\
\text { das ações). }\end{array}$ & $\begin{array}{c}\text { Frequente. } \\
\text { Crianças } \\
\text { usuárias do SUS, } \\
\text { identificadas com } \\
\text { obesidade. }\end{array}$ & $\begin{array}{l}\text { Nutróloga pediatra, } \\
\text { nutricionista, } \\
\text { endocrinologista, } \\
\text { nefrologista e } \\
\text { psicólogo. }\end{array}$ \\
\hline
\end{tabular}

DCNT: doenças crônicas não transmissíveis; SUS: Sistema Único de Saúde; UBS: unidades básicas de saúde.

esse estudo, seu potencial refere-se à possibilidade de estabelecer em um dado território uma infraestrutura voltada diretamente para ações de promoção da saúde, com equipe multiprofissional que favoreça a convivência, sociabilidade e realização da atividade física integrada a um conjunto amplo de ações de PAAS. O estudo sinaliza que a operacionalização do programa depende de infraestrutura e recursos próprios, inclusive equipe multiprofissional que atue para promover uma abordagem integrada. No entanto, a pouca familiaridade dos nutricionistas que atuam na RAS com a preparação do programa pode indicar fragilidades na articulação das ações de PAAS e atividade física 25.

A assistência terapêutica multiprofissional vem sendo considerada estratégica para a promoção do cuidado integral do indivíduo com obesidade 7,11, contudo, o relato dos profissionais, especialmente os da área de nutrição, não indica que se trata de uma realidade amplamente vivenciada na APS nos municípios do Estado do Rio de Janeiro. Ainda assim, algumas iniciativas se destacam, como o processo de estruturação da Linha de Cuidado do Sobrepeso e Obesidade da região Norte do estado do Rio de Janeiro. Essas iniciativas fortalecem os laços de cuidado e fornecem integração entre os profissionais e os usuários, favorecendo as ações vigentes (Quadro 4).

A efetividade da equipe multiprofissional para o atendimento ao indivíduo obeso é evidenciada por alterações positivas nos indicadores antropométricos, bioquímicos e psicossociais 26 . O estudo que analisou o componente ambulatorial da Linha de Cuidado do Sobrepeso e Obesidade na cidade do Rio de Janeiro também ressaltou as mudanças positivas no estilo de vida e nas práticas de indivíduos com acompanhamento multiprofissional 27. 
Uma ação reiteradamente proposta nos documentos e destacada nos depoimentos dos profissionais e gestores do Estado do Rio de Janeiro é a atividade de grupos como estratégia de educação alimentar e nutricional, com destaque para o resgate da culinária 5. Ressalta-se o investimento da ATAN estadual na formação de profissionais em oficinas culinárias visando à sua operacionalização em diferentes espaços da APS. A literatura registra o potencial terapêutico das atividades de grupo, especialmente quando combinadas a outros tipos de ação 13,18, e experiências inovadoras vêm sendo divulgadas 28 .

\section{Potencialidades e desafios para a implantação das ações}

O Quadro 3 apresenta os programas do Governo Federal implantados localmente e destacados pelos depoentes por seu potencial impacto no sobrepeso e obesidade. Dentre os citados, as academias da saúde e os programas/ações implantados nas escolas potencialmente contribuem para afetar os contextos e ambientes por meio da oferta de alimentação saudável e da prática de atividade física. Os demais são voltados à abordagem individual ou visam a afetar as práticas de grupos específicos. $\mathrm{O}$ Quadro 4 apresenta as ações de iniciativa municipal que incidem apenas sobre práticas alimentares inadequadas e sedentarismo, ou seja, interferem fundamentalmente em condutas e práticas individuais/de grupos específicos mais do que nos contextos que condicionam estas práticas.

O Programa Nacional de Alimentação Escolar (PNAE) foi pouco abordado pelos depoentes, ainda que a alimentação escolar em si tenha sido amplamente referida. Os gestores e profissionais indicaram que a abordagem na ótica da promoção da saúde, e mesmo da prevenção da doença, ainda é frágil quando comparada ao peso das ações de controle (como consultas após diagnóstico tardio e cirurgia). Um estudo sobre estratégias e desafios da gestão da APS no controle e prevenção do sobrepeso e obesidade ressaltou a importância da reorganização dos serviços da APS com ênfase na promoção da saúde 29 .

Os principais condicionantes da obesidade que vêm sendo potencialmente afetados pelos programas/ações referem-se à ampliação do acesso à informação qualificada sobre alimentação saudável e sobre o estado nutricional, este último proporcionado principalmente pela vigilância alimentar e nutricional e PSE, sem desconsiderar seus limites de implantação, além da diversificação da dietética e das formas de preparo dos alimentos, especialmente por meio da educação alimentar e nutricional. As Academias da Saúde potencialmente afetam condicionantes importantes da obesidade como a oferta e a disponibilidade de locais adequados para práticas de atividade física. No entanto, segundo dados de 2018 (Ministério da Saúde. Relatórios Públicos dos Sistemas da Atenção Básica. https://egestorab. saude.gov.br/paginas/acessoPublico/relatorios/relatoriosPublicos.xhtml, acessado em 20/Fev/2019), existiam nove polos do Programa Academia da Saúde implantados e apenas um em funcionamento pleno no Estado do Rio de Janeiro. Além disso, o NASF estava implantado em 63 municípios e o PSE pactuado em 88 municípios do Estado do Rio de Janeiro, sem, contudo, abranger a totalidade do território e das escolas.

As ações de educação alimentar e nutricional, quando são ampliadas para além da transmissão de informações e abarcam, por exemplo, práticas culinárias e compartilhamento de vivências em uma perspectiva dialógica, têm forte potencial de afetar condicionantes do sobrepeso e obesidade relacionados com as formas de preparo dos alimentos, a cultura alimentar, a sociabilidade e até mesmo os fatores psicossociais 9 .

No âmbito das atribuições da gestão municipal, as ações regulatórias que mais se destacaram referem-se à regulação do ambiente escolar, especialmente das cantinas e da publicidade de alimentos ultraprocessados nestes locais, pois são instituições geridas por este nível de gestão (nível fundamental de ensino sob a responsabilidade municipal e nível médio sob a responsabilidade estadual) 29 .

Os programas cujo desenho operacional tem como fundamento o princípio da intersetorialidade, como o PSE e o Programa Bolsa Família, aportam, segundo Souza et al. 23, ações fortemente circunscritas à educação alimentar e nutricional e ao diagnóstico nutricional. Ainda assim, considerando que o desenho operacional desses programas prevê instâncias institucionais integradas por representantes das secretarias de saúde, educação e assistência, há alguma potencialidade para o desenvolvimento de ações integradas. Considerando os limites deste estudo, a análise do processo de operacionalização 
desses programas nos municípios não foi realizada, indicando a relevância de pesquisas que aprofundem tal perspectiva.

Em outros estados e municípios do país o cenário de ações é semelhante ao do Estado do Rio de Janeiro, como em Santos (São Paulo) 30 onde entre 2013 e 2015 a atenção nutricional compreendia apenas o atendimento individual, referência/contrarreferência, diagnóstico nutricional, e as ações de promoção da saúde só ocorriam quando o excesso de peso se associava a outra enfermidade.

Uma pesquisa realizada em dois municípios do Rio Grande do Norte 31 identificou a não permanência diária e a baixa assiduidade dos profissionais, particularmente dos médicos, como fator contribuinte para que as ações de promoção à saúde se limitassem a palestras. Os usuários indicaram a falta de local adequado para a assistência, falta de estrutura e equipamentos básicos como circunstâncias "normais" na zona rural, e mesmo a ausência de "posto de saúde" em algumas localidades, que dificultam a implantação de ações e a garantia do cuidado integral ao indivíduo obeso ${ }^{31}$.

Um dos desafios destacados pelas referências municipais e regionais das ATAN no Estado do Rio de Janeiro foi a rotatividade e o quantitativo insuficiente de profissionais de saúde, principalmente de nutricionistas, dificultando o encaminhamento dos pacientes, resultando no aumento da fila de espera e sobrecarga de trabalho. Além disso, algumas atividades que compõem o trabalho dos diversos profissionais da APS são identificadas como de responsabilidade do nutricionista, o que reforça essa sobrecarga e dificulta uma abordagem multidisciplinar do tema.

Outro desafio da gestão municipal refere-se às múltiplas funções dos nutricionistas, uma vez que grande parte deles atua simultaneamente como gestores de nível central e profissional da RAS, por vezes em diferentes municípios. As múltiplas tarefas podem reduzir o tempo dedicado à gestão dos programas e afetar o potencial de integração das ações e serviços, dificultando a realização de atividades para além das consultas clínicas, especialmente aquelas que demandam diálogo intersetorial ou interdisciplinar.

Esses limites foram corroborados em um estudo realizado num município paulista de médio porte 32 que identificou dificuldades na estrutura física das unidades de saúde, falta de profissionais e grande demanda por atendimento. Igualmente, o estudo realizado em Campinas (São Paulo) 33 sinalizou a ausência de espaço físico, falta de recursos humanos e de profissionais capacitados como determinantes para a não realização de atividades educativas nas unidades de saúde.

Contudo, não é "apenas" a falta de tempo decorrente das demandas de atendimento que pode favorecer o uso de métodos educativos e condutas terapêuticas tradicionais, mas a própria formação profissional pode reforçar práticas prescritivas e pouco dialógicas, além dos desafios que o profissional encontra para lidar com a complexidade da obesidade. Diferentes entrevistados relataram como desafio a falta ou a fragilidade de um planejamento de ações especificamente direcionadas à obesidade. Segundo Assis 34, é significativa a dificuldade dos profissionais em identificar e lidar com as ações de prevenção da obesidade devido à formação inadequada, à falta de conhecimento sobre as ações mais efetivas e de articulação com outros profissionais habilitados.

A tendência a uma formação centrada em parâmetros e condicionantes biomédicos pode contribuir para tais desafios. A abordagem terapêutica de outras doenças crônicas (como diabetes e hipertensão) parece ser, ao menos em tese, mais tangível aos profissionais, considerando-se os protocolos terapêuticos centrados em medicamentos e regulação do comportamento por meio de restrições específicas (reduza o sal, evite açúcar). Esse tipo de abordagem pode estar sendo adotada também como terapêutica prioritária para a obesidade na ausência de uma compreensão mais sistêmica sobre o problema.

Alguns municípios do Estado do Rio de Janeiro vêm potencializando ações de prevenção e controle da obesidade por meio dos seus planos de governo. O Plano Municipal de Itatiaia (Rio de Janeiro) 2017-2020 propõe, dentro da esfera da educação, a garantia do acompanhamento da obesidade infantil nas escolas municipais 35; o Plano Municipal de Saúde de Angra dos Reis 2018-2021 propõe, no eixo de programas de saúde, o fortalecimento da divulgação e realização de atividades educacionais com base no Guia Alimentar para a População Brasileira, visando a atender a necessidade da promoção da alimentação saudável 36 .

Outros municípios brasileiros também vêm implantando ações semelhantes ao Estado do Rio de Janeiro, como Palmas (Tocantins) que elaborou em 2015 o Plano Municipal de Prevenção e Controle da Obesidade 37 e Paranaguá (Paraná), que criou um Programa Municipal de prevenção e controle da 
obesidade em crianças e adolescentes por meio de Lei que estabelece multa em valores reais caso não seja cumprida qualquer uma das normas referidas 38 .

No mesmo ano da publicação do manual instrutivo da Linha de Cuidado do Sobrepeso e Obesidade 17, o Município de São Paulo divulgou uma proposta de Linha de Cuidado do Sobrepeso e Obesidade regional 39 que expõe as ações vigentes nas unidades básicas de saúde (UBS), o fluxo construído da Linha de Cuidado do Sobrepeso e Obesidade e o cronograma de apoio para sua implantação e manutenção.

As iniciativas identificadas nos municípios do Estado do Rio de Janeiro e em outros estados indicam que a obesidade tem ganhado destaque nas pautas governamentais, e a literatura internacional destaca também algumas ações em curso, desafios e potencialidades, e uma revisão sistemática indica a relevância das políticas regulatórias de alimentos ${ }^{40}$. Além disso, um estudo realizado na Austrália mapeou as iniciativas comunitárias de prevenção da obesidade vigentes, identificando 259 , sendo que a maioria abordava ações de alimentação saudável e práticas de atividade física ${ }^{41}$.

Um artigo sobre um programa vinculado à Plataforma de Avaliação em Prevenção da Obesidade de Quebec (Canadá) identificou como ações potenciais de prevenção da obesidade: a promoção da alimentação adequada e atividade física para toda população, promoção da amamentação, melhoria da qualidade dos alimentos e bebidas oferecidos nas escolas e creches, entre outras 42 .

\section{Considerações finais}

As principais ações de prevenção e controle da obesidade propostas nas políticas públicas nacionais e desenvolvidas no Estado do Rio de Janeiro têm significativa aplicabilidade nas condutas de segmentos específicos, ou seja, operam por meio de ações que visam a afetar diretamente tais condutas, especialmente com base na ampliação do acesso à informação adequada sobre alimentação. Aqueles operacionalizados nas escolas, como o PSE e o PNAE (que foge ao escopo da APS), são diretamente voltados para escolares e os demais atendem os diferentes segmentos abrangidos pela RAS (crianças, adolescentes, adultos). As ações que potencialmente afetam os contextos, por meio da oferta de locais adequados para prática de atividade física, referem-se ao Programa Academia da Saúde. Além disso, pode-se considerar que as macropolíticas aqui identificadas como constitutivas, baseando-se na taxonomia de Lowi ${ }^{10}$, também têm como foco mais amplo os ambientes e contextos onde as práticas de saúde são construídas.

Para além das políticas induzidas pelo Governo Federal identificaram-se iniciativas municipais específicas que indicam um movimento local, ainda que incipiente e pontual. As políticas do tipo regulatórias que vêm sendo implantadas pelos municípios referem-se principalmente à regulação de cantinas e da publicidade de alimentos nas escolas, considerando as especificidades das atribuições deste nível de governo.

Alguns desafios para a implantação foram destacados, especialmente: o escopo restrito de ações de alguns programas e cobertura limitada, como sinalizados em relação à vigilância alimentar e nutricional, ao PSE e à Academia da Saúde; o quantitativo insuficiente de profissionais e a rotatividade que afetam a manutenção das ações e dos fluxos de atendimento, e a construção de vínculo entre os profissionais e usuários, bem como a possibilidade de consolidar equipes multiprofissionais. Destaca-se a importância da articulação entre profissionais da nutrição e da educação física em programas como a Academia da Saúde.

A inadequação dos espaços físicos e equipamentos da APS para o acolhimento da pessoa com obesidade também é desafiadora. Os centros de atendimento especializado para obesidade e/ou DCNT em geral dispõem de equipes multiprofissionais, espaço físico e equipamentos adequados, e cabe integrá-los de forma mais orgânica à RAS, para que não se instituam como espaços "paralelos" ao próprio sistema.

A ampliação do planejamento governamental, bem como do processo terapêutico, para além de uma abordagem da obesidade focada no fator de risco para DCNT, pode contribuir para que as ações relacionadas ao tema não fiquem pulverizadas dentro da RAS. 


\section{Colaboradores}

D. B. N. Ramos, L. Burlandy, P. C. Dias e P. Hemriques contribuíram na concepção e delineamento do estudo, coleta e análise dos dados, redação e revisão crítica do manuscrito. L. M. C. Castro, M. R. M. Teixiera, C. R. Bocca, T. S. Araújo, F. A. Caldas, T. R. Souza, S. R. Souza e M. C. C. Cruz contribuíram na coleta e análise dos dados e revisão crítica do manuscrito.

\section{Informações adicionais}

ORCID: Doralice Batista das Neves Ramos (00000003-0572-0915); Luciene Burlandy (0000-00030875-6374); Patrícia Camacho Dias (0000-00020674-8832); Patrícia Henriques (0000-0001-81540962); Luciana Maria Cerqueira Castro (00000003-2793-9950); Márcia Regina Mazalotti Teixeira (0000-0002-3528-5814); Cláudia Roberta Bocca (0000-0002-4312-3049); Thays da Silva Araujo (0000-0001-8688-9741); Fernando de Andrade Caldas (0000-0002-7636-3321); Thamillys Rodrigues Souza (0000-0002-4328-4256); Simone Raimondi de Souza (0000-0003-1636-7459); Myrian Coelho Cunha Cruz (0000-0002-6945-4890).

\section{Agradecimentos}

Os autores agradecem o financiamento feito pela Fundação de Amparo à Pesquisa do Estado do Rio de Janeiro (FAPERJ) por meio do Edital PPSUS $\backslash$ FAPERJ - E - 26\110.293\2014; ao Programa de Pós-graduação em Ciências da Nutrição da Universidade Federal Fluminense e à Coordenação de Aperfeiçoamento de Pessoal de Nível Superior (CAPES).

\section{Referências}

1. Câmara Interministerial de Segurança Alimentar e Nutricional. Estratégia Intersetorial de Prevenção e Controle da Obesidade: recomendações para estados e municípios. Brasília: Câmara Interministerial de Segurança Alimentar e Nutricional; 2014.

2. Secretaria de Vigilância em Saúde, Ministério da Saúde. Vigitel Brasil 2018: vigilância de fatores de risco e proteção para doenças crônicas por inquérito telefônico: estimativas sobre frequência e distribuição sociodemográfica de fatores de risco e proteção para doenças crônicas nas capitais dos 26 estados brasileiros e no Distrito Federal em 2018. Brasília: Ministério da Saúde; 2019.

3. Instituto Brasileiro de Geografia e Estatística. Pesquisa Nacional de Saúde 2013: percepção do estado de saúde, estilos de vida e doenças crônicas - Brasil, Grandes Regiões e Unidades da Federação. Rio de Janeiro: Instituto Brasileiro de Geografia e Estatística; 2014.

4. Dias PC, Henriques P, Anjos LA, Burlandy L. Obesidade e políticas públicas: concepções e estratégias adotadas pelo governo brasileiro. Cad Saúde Pública 2017; 33:e00006016.

5. Ministério da Saúde. Estratégias para o cuidado da pessoa com doença crônica. Obesidade. Brasília: Ministério da Saúde; 2014. (Cadernos de Atenção Básica, 38).

6. Ministério da Saúde. Portaria no 4.279, de 30 de dezembro de 2010. Estabelece diretrizes para organização da RAS no âmbito do SUS. Diário Oficial da União 2010; 31 dez.

7. Ministério da Saúde. Portaria no 424, de 19 de março de 2013. Redefine as diretrizes para a organização da prevenção e do tratamento do sobrepeso e obesidade como linha de cuidado prioritária da Rede de Atenção à Saúde das Pessoas com Doenças Crônicas. Diário Oficial da União 2013; 20 mar.

8. Ministério da Saúde. Portaria no 425, de 19 de março de 2013. Estabelece regulamento técnico, normas e critérios para a Assistência de Alta Complexidade ao Indivíduo com Obesidade. Diário Oficial da União 2013; 20 mar.

9. Henriques P, O’Dwyer G, Dias PC, Barbosa RMS, Burlandy L. Políticas de Saúde e de Segurança Alimentar e Nutricional: desafios para o controle da obesidade infantil. Ciênc Saúde Colet 2017;23:4143-52.

10. Lowi T. Four systems of policy, politics, and choice. Public Administration Review 1972; 32:298-310.

11. Ministério da Saúde. Portaria no 2.436, de 21 de setembro de 2017. Aprova a Política Nacional de Atenção Básica, estabelecendo a revisão de diretrizes para a organização da Atenção Básica, no âmbito do Sistema Único de Saúde (SUS). Diário Oficial da União 2017; 22 set.

12. Ministério da Saúde. Política Nacional de Atenção Básica. Brasília: Ministério da Saúde; 2006. (Série A. Normas e Manuais Técnicos) (Série Pactos pela Saúde 2006, 4). 
13. Departamento de Atenção Básica, Secretaria de Atenção à Saúde, Ministério da Saúde. Política Nacional de Atenção Básica. Brasília: Ministério da Saúde; 2012. (Série E. Legislação em Saúde)

14. Ministério da Saúde. Portaria no 2.446, de 11 de novembro de 2014. Redefine a Política Nacional de Promoção da Saúde (PNPS). Diário Oficial da União 2014; 12 nov.

15. Ministério da Saúde. Portaria GM/MS no 483, de 1 de abril de 2014. Redefine a Rede de Atenção à Saúde das Pessoas com Doenças Crônicas no âmbito do Sistema Único de Saúde (SUS) e estabelece diretrizes para a organização das suas linhas de cuidado. Diário Oficial da União 2014; 2 abr.

16. Ministério da Saúde. Portaria GM/MS no 62, de 6 de janeiro de 2017. Altera as Portarias no 424/GM/MS de 19 de março de 2013, que redefine as diretrizes para a organização da prevenção e do tratamento do sobrepeso e obesidade como linha de cuidado prioritária na Rede de Atenção às Pessoas com Doenças Crônicas e no 425/GM/MS de 19 de março de 2013, que estabelece o regulamento técnico, normas e critérios para a Assistência de Alta Complexidade ao Indivíduo com Obesidade. Diário Oficial da União 2017; 9 jan.

17. Ministério da Saúde. Organização regional da Linha de Cuidado do Sobrepeso e da Obesidade na rede de atenção à saúde das pessoas com doenças crônicas. Manual instrutivo. Brasília: Ministério da Saúde; 2014.

18. Departamento de Atenção Básica, Secretaria de Atenção à Saúde, Ministério da Saúde. Obesidade. Brasília: Ministério da Saúde; 2006. (Cadernos de Atenção Básica, 12).

19. Departamento de Atenção Básica, Secretaria de Atenção à Saúde, Ministério da Saúde. Estratégias para o cuidado da pessoa com doença crônica. Brasília: Ministério da Saúde; 2014. (Cadernos de Atenção Básica, 35).

20. Ministério da Saúde. Diretrizes do NASF: Núcleo de Apoio a Saúde da Família. Brasília: Ministério da Saúde; 2010. (Cadernos de Atenção Básica, 27).

21. Subsecretaria de Atenção à Saúde, Secretaria de Estado de Saúde do Rio de Janeiro. Plano de ações estratégicas para o enfrentamento das doenças crônicas não transmissíveis (DCNTs) no Estado do Rio de Janeiro, 2013-2022. Rio de Janeiro: Secretaria de Estado de Saúde do Rio de Janeiro; 2012.

22. Ministério da Saúde. Plano de ações estratégicas para o enfrentamento das doenças crônicas não transmissíveis (DCNT) no Brasil 20112022. Brasília: Ministério da Saúde; 2011.

23. Sousa MC, Esperidião MA, Guadalupe MM. A intersetorialidade no Programa Saúde na Escola: avaliação do processo político-gerencial e das práticas de trabalho. Ciênc Saúde Colet 2017; 22:1781-90.

24. Secretaria de Atenção Primária à Saúde, Ministério da Saúde. Programa Crescer Saudável 2019/2020 - instrutivo. Brasília: Ministério da Saúde; 2019.
25. Cavalcante EFL. Planejamento e coordenação de ações de alimentação e nutrição: enfrentamento do sobrepeso e da obesidade no Município do Rio de Janeiro [Tese de Doutorado]. Rio de Janeiro: Escola Nacional de Saúde Pública Sergio Arouca, Fundação Oswaldo Cruz; 2017.

26. Mendes AA, Ieker ASD, Castro TF, Avelar A, Nardo Júnior N. Programas multidisciplinares para tratamento da obesidade no Brasil: uma revisão sistemática. Rev Nutr 2016; 29:867-84.

27. Reis EC. Avaliação do componente ambulatorial especializado da linha de cuidado para obesidade grave na Cidade do Rio de Janeiro [Tese de Doutorado]. Rio de Janeiro: Escola Nacional de Saúde Pública Sergio Arouca, Fundação Oswaldo Cruz; 2018.

28. Ministério da Saúde; Organização Pan-Americana da Saúde. Perspectivas e desafios no cuidado às pessoas com obesidade no SUS: resultados do Laboratório de Inovação no manejo da obesidade nas Redes de Atenção à Saúde. Brasília: Ministério da Saúde; 2014.

29. Almeida LM, Campos KFC, Randow R, Guerra VA. Estratégias e desafios da gestão da Atenção Primária à Saúde no controle e prevenção da obesidade. Rev Gest Saúde (Brasília) 2017; 8:114-39.

30. Neves JA, Zangirolani LTO, Medeiros MAT. Avaliação do atendimento nutricional de adultos com excesso de peso na perspectiva da atenção integral à saúde. Rev Nutr 2017; 30:511-24

31. Uchoa AC, Souza E, Spinelli AFS, Medeiros RG, Peixoto DCS, Silva RAR, et al. Avaliação da satisfação do usuário do Programa de Saúde da Família na zona rural de dois pequenos municípios do Rio Grande do Norte. Physis (Rio J.) 2011; 21:1061-76.

32. Maximiano TO. Percepção de gestores e profissionais da saúde sobre a linha de cuidado do sobrepeso e da obesidade [Dissertação de Mestrado]. Botucatu: Faculdade de Medicina, Universidade Estadual Paulista Júlio de Mesquita Filho; 2016.

33. Carrara APB, França EA, Bonino MV, Brochetto MFD, Ribeiro RL, Costa ECS, et al. Obesidade: um desafio para a saúde pública. J Health Sci Inst 2008; 26:299-303.

34. Assis CN. Práticas de cuidado às pessoas com excesso de peso no sistema saúde: onde ficam os sujeitos e a subjetividade? [Dissertação de Mestrado]. Rio de Janeiro: Programa de PósGraduação em Saúde Coletiva, Universidade do Estado do Rio de Janeiro; 2017.

35. Prefeitura Municipal de Itatiaia. Plano de governo de Itatiaia - 2017/2020. Itatiaia: Prefeitura Municipal de Itatiaia; 2016.

36. Departamento de Planejamento, Controle, Auditoria, Avaliação e Regulação, Secretaria Municipal de Saúde, Prefeitura Municipal de Angra dos Reis. Plano municipal de saúde de Angra dos Reis, 2018-2021. Angra dos Reis: Prefeitura Municipal de Angra dos Reis; 2017. 
37. Secretaria Municipal de Saúde, Prefeitura Municipal de Palmas. Plano municipal de prevenção e controle da obesidade. Palmas: Prefeitura Municipal de Palmas; 2015.

38. Câmara Municipal de Paranaguá. Lei no 3015 , de 23 de novembro de 2009. Cria o programa municipal de prevenção e controle da obesidade em crianças e adolescentes em Paranaguá e dá outras providências. Diário Oficial 2009; 24 nov.

39. Secretaria Municipal de Saúde, Prefeitura Municipal de São Paulo. Linha de Cuidado de Sobrepeso e Obesidade da Rede de Atenção à Saúde das pessoas com Doenças Crônicas RRAS6 - São Paulo. São Paulo: Prefeitura Municipal de São Paulo; 2014.
40. Sebastián-Ponce MI, Sanz-Valero J, WandenBerghe C. Etiquetado y rotulación de los alimentos en la prevención del sobrepeso y la obesidad: una revisión sistemática. Cad Saúde Pública 2011; 27:2083-94.

41. Whelan J, Love P, Romanus A, Pettman T, Bolton K, Smith E, et al. A map of communitybased obesity prevention initiatives in Australia following obesity funding 2009-2013. Aust N Z J Public Health 2015; 39:168-71.

42. Le Bodo Y, Blouin C, Dumas N, De Wals P, Lague J. The Quebec experience in promoting healthy lifestyles and preventing obesity: how can we do better? Obes Rev 2017; 18:967-86. 


\section{Abstract}

The article analyzes actions in the prevention and control of overweight and obesity that have been developed in the 92 municipalities (counties) in the state of Rio de Janeiro, Brazil, based on underlying principles in the typology of public policies developed by Lowi and Line of Care for Overweight and Obesity, according to the following analytical dimensions: program actions in prevention and control of obesity, characterization of macro policies according to the Lowi typology, and characterization of macro policies according to the Line of Care for Overweight and Obesity. The study is part of a research project from 2014 to 2018 that aimed to identify the strategies and challenges in the consolidation of the actions planned in the Line of Care for Overweight and Obesity, based on analysis of secondary data and government documents; searches in the municipalities' official websites; interviews; focus groups; and online questionnaires with health professionals and managers. The documents point to a series of actions such as individual consultations, support groups, health gyms, school health programs, and others, reinforced by the interviewees' narratives. Even with so many initiatives, the municipalities in the state of Rio de Janeiro face challenges with limited human resources and precarious infrastructure and equipment in the health units. To achieve mobilization in the actions to deal with obesity, the issue should be addressed specifically on the state and local agendas and not diluted among other activities and programs.

Obesity; Public Policy; Primary Health Care

\section{Resumen}

Este artículo analiza las acciones de prevención y control del sobrepeso y de la obesidad que se están desarrollando en 92 municipios del estado de Río de Janeiro, Brasil, basándose en los principios que fundamentan la tipología clásica de políticas públicas, desarrollada por Lowi, y la Línea de Cuidado del Sobrespeso y de la Obesidad, a partir de las siguientes dimensiones de análisis: programas $y$ acciones de prevención y control de la obesidad, caracterización de macropoliticas, según la tipología de Lowi, y caracterización de las acciones, según los principios de la Línea de Cuidado del Sobrespeso y de la Obesidad. El estudio forma parte de una investigación, realizada entre 2014 y 2018, cuyo objetivo fue identificar las estrategias adoptadas y los desafíos enfrentados para consolidar las acciones previstas en la Línea de Cuidado del Sobrespeso y de la Obesidad, en base a los métodos de análisis de datos secundarios y documentos gubernamentales; búsqueda en sitios web oficiales de los municipios; entrevistas, grupos focales y cuestionarios electrónicos con profesionales $y$ gestores de salud. Los documentos apuntan una serie de acciones como: consulta individual, grupos de apoyo, academia de salud, programa salud en la escuela, entre otros, que fueron reforzados por las narraciones de los entrevistados. Incluso ante tantas iniciativas, los municipios del estado do Río de Janeiro deben superar desafíos como: recursos humanos reducidos y estructura de unidades $y$ equipamientos de salud precarios. Para que haya una mayor movilización en lo referente a las acciones frente a la obesidad, el tema debe ser tratado de forma particular en las agendas estatales y municipales, y no encontrarse diluido dentro de otras acciones y programas.

Obesidad; Poíticas Públicas; Atención Primária de Salud
Recebido em 19/Jun/2019

Versão final reapresentada em 01/Nov/2019

Aprovado em 02/Dez/2019 